\title{
David Clarke's Analytical Archaeology at 50
}

\author{
Stephen J. Lycett ${ }^{1}$ and Stephen J. Shennan ${ }^{2}$
}

${ }^{1}$ Department of Anthropology, University at Buffalo, The State University of New York (SUNY), Amherst, New York 14261, USA. Email: sjlycett@buffalo.edu

${ }^{2}$ Institute of Archaeology, University College London, 31-34 Gordon Square, London WC1H OPY, UK

\begin{abstract}
David Clarke's (1968) Analytical Archaeology has been seen as a pivotal work that emerged when new ideas and approaches were transforming archaeology as a discipline. However, we contend that some of its key ideas have only been picked up on and given closer consideration in more recent years. At the 50th anniversary of its publication, we outline the central ideas discussed in Analytical Archaeology and evaluate its role in ongoing discussions. We conclude that in the light of recent work, which can demonstrably be seen as revisiting some of its central themes, there is much to be gained in contemporary archaeological discussion by revisiting Clarke's book.
\end{abstract}

Keywords: Archaeological theory; Cultural evolution; Cultural transmission; Artefactual variation; Cultural patterns 
Commenting on a book that is half a century old perhaps requires some justification. Some might most obviously point to the fact that David Clarke's (1968) Analytical Archaeology (hereafter $A A$ ) is widely recognized as having been a pivotal publication in 20th century archaeology, most especially as part of the birth of 'New' or 'Processual' Archaeology (see e.g., Trigger 1989; Johnson 1999). However, in an age where discussion of 'isms' is perhaps less fashionable than it once was, others might equally see this as relegating a once-famous text to little more than a sideline within disciplinary history. Alternatively, the death of Lewis Binford in 2011 might have reminded us that of the many things that David Clarke's untimely death robbed him (and the archaeological world) of was that sort of 'end of life' celebration and evaluation of a great thinker's work which invariably occurs with their departure. Of course, that to some extent happened earlier for Clarke with a smattering of such evaluations having emerged shortly after his death in 1976 (Hammond et al. 1979; Hodder et al. 1981). However, overall, the 'mature' fifty-year perspective was lost in a way to Clarke that it was not to Binford.

While these might seem reasonable justifications on their own, our motivations for writing this commentary are more than simply nostalgia. Some years ago, a commentary appeared (Shennan 1989) that evaluated the relative contributions of both Clarke's $A A$ and Sally and Lewis Binford's New Perspectives, which was published the same year (Binford and Binford 1968). This commentary recognized the immense influence that the Binfords' edited book had on the field and suggested that many of its most striking lessons had largely been learnt. The evaluation of Clarke's book was somewhat different: "Analytical Archaeology, on the other hand, has remained a curiosity and has had virtually no influence whatsoever" (Shennan 1989: 831). The paper went on to say that there were few studies that actually operationalized its central ideas (Shennan 1989: $833)$.

We thought it appropriate to re-evaluate these statements, especially in the light of recent work within the field that might be seen to be returning to some of the key issues discussed in $A A$. We first review some of the central ideas of $A A$ particularly those ideas which according to Shennan (1989) had appeared to leave unfinished business. Many of Clarke's ideas might be seeing greater discussion today. However, whether this is direct influence rather than re-invention or inspiration from alternative sources is still questionable. Accordingly, we will argue that it might be beneficial for a younger generation of archaeologists to re-visit the original for fresh insight. 


\section{An analytical archaeology of the morphology of past culture}

The abstruse and challenging character of the terminology, language and ideas presented in $A A$ has been commented on widely (e.g., Chapman 1979: 109; Sherratt 1979: 197; O'Brien 2010: 317). In many respects the structure of the book is deceptively simple. It begins with an outline of some of its main claims and premises, in an introduction that its own author described as "polemic" (Clarke 1968: 3). Thereafter, the book outlines systems theory (chapter 2), the nature of culture as information (chapter 3), the hierarchical taxonomy of archaeological data as comprised of attributes, artefacts, types, assemblages, culture groups and techno-complexes (chapters 4-8), discusses how ethnographic data may and may not relate to archaeologically observable entities (chapter 9), followed by further consideration of the processes by which archaeological entities are gained, lost and transformed over time and space (chapter 10). The second part of the book (titled "Method") dealt with numerical taxonomy and statistical procedure, computer methods and case studies, which given the pioneering nature of the overall framework, were inevitably not always ideally suited to his purpose (chapters 11-13). The book ends with a chapter (14) that beguilingly bears the title "Summary and conclusions".

Such a structure belies the complexity and density of ideas that are crammed within its 664 pages. That Clarke took over 226 pages to describe how the archaeological record is comprised of attributes, artefacts, types, assemblages, and further more cumbersome conglomerations of these, would alone indicate that something more is present. This is perhaps, in part, the consequence of the density and richness of the diffuse ideas that were being exposed for the first time by a man who was (incredibly perhaps in retrospect) only 30 years old at the time of writing them. At times $A A$ can certainly be frustrating. On page 182 , Clarke showed a widely reproduced diagram titled "How pattern gets into the system", which with hindsight can be seen as an early attempt to model social learning within the context of artefactual attribute variation within and across populations of artefacts. This diagram is connected (via caption) with two others, one on page 639 and one on page 650 , almost at the book's close. In this diagram he also introduced terms that were key to understanding the wider ideas it contained, such as 'Designata', 'Concepta' and 'Percepta'. These terms were not actually defined, however, until page 649. Similarly, polythetic (nondiscrete) units are first discussed at length on pages 37-38, a diagram that illustrates aspects relevant to this is shown on page 56, illustrated and extended again in relation to previous concepts on page 246, 
illustrated and extended again on page 300, and finally discussed and illustrated again on page 367 in the context of ethnographic examples. Of course, this to some extent might be used as evidence of the strong themes and strains of thought that run over extended sections of the book's 664 pages, and this would certainly be correct. Nevertheless, the disjunction between elements that can, and should, only be understood in relation to each other is a feature that also characterizes $A A$. This is especially problematic given the barrage of thoughtful and provocative elements that occur within the intervening pages making the reader work harder still to maintain a sense of connection. To some extent, $A A$ can usefully be approached not as a single narrative, but as the published 'notebooks' of an insightful and provocative thinker. We hasten to stress that we do not strictly mean to imply that this is what $A A$ is, which would do disservice to the structure of the book Clarke imposed and the overarching narratives and themes that thread their way through the text. However, we suggest that such a mindset may help prepare the reader, both for the nature of the task ahead of them, and in so achieving that task.

Ironically, given what we have just said, much of $A A$ can essentially be seen as an argument for precision (Clarke 1968: 19). That is, precision in scales of archaeological description; in the terminology used to describe socio-cultural processes that might relate to archaeological data; and, precision of logic, procedure and method. As has been widely commented on over the intervening years, much of the latter focussed on the role of quantitative data and statistical methods. Of course, methodological, computational and statistical procedures within archaeological research have increased and diversified in a variety of ways in recent decades, as seen in everything from use of ancient genomic data through to large-scale, statistical radiocarbon dating programmes (Griffiths 2017). However, Clarke emphasized a need for terminological, logical and theoretical precision at least as much as methodological precision.

Beyond this, the book pushed several additional messages. These included the systemic nature of cultural systems and their time transgressive character; that culture (crucially) is an information system that people share across time and space; that cultural entities are polythetic (i.e., intersecting in at least some attributes and essentially not discrete); that the units and patterns identified in space and time are no less 'real' and no less 'arbitrary' than those observed by the ethnographer, they are simply different. Moreover, although he was not direct in expressing it, Clarke identified that cultural systems, and the archaeological data derived from them, bore the 
essential properties and consequences of an evolutionary system of descent with modification. To make sense of these issues, $A A$ unabashedly pushed one further message. However much archaeology can and should draw on other disciplines as sources of ideas, methods, and concepts in understanding human cultural systems, the field of archaeology possessed "peculiar data" with respect to its ultimate aims $(A A: 14)$. These peculiar data - artefacts, their attributes and their variation and dispersion in time and space - makes archaeology "a discipline in its own right" ( $A A$ : 13). In contrast to Binford (1962), who followed Willey and Phillips (1958: 2) in proclaiming that "archaeology is anthropology or it is nothing", Clarke was emphatic in concluding that "archaeology, is archaeology, is archaeology" ( $A A$ : 13). This put material 'stuff' at the centre of archaeological endeavour and stressed its unique temporal and spatial aspects of form (changing and stable) as its crucial strength. Archaeology was relevant to, and had to connect with, other disciplines, but its data and contribution were unique, as was the required approach.

To comment further on just some of these issues. Clarke was not simply content to bemoan the fact that archaeological patterns might not be of the same type or mean the same thing as those observed by anthropologists among living peoples studying human behaviour directly. For Clarke ( $A A: 372$ ), archaeological patterns that could be identified in time and space "are not one whit less significant than the tribal, linguistic, or historical sets - they are just different". Clarke saw these in some sense marking points of social interaction, stating that archaeological spatio-temporal patterns constitute "a real entity that really existed marking real interconnection" their lack of connection to ethnolinguistic entities "does not make it less real or important" ( $A A$ : 364$)$. This is not to say that ethnography or anthropological issues were not of central concern to archaeologists, as chapter 9 of $A A$ makes abundantly clear. Rather, these comments need to be seen in the context of the book's emphasis on the delineation of archaeological patterns and entities - in explicitly archaeological (i.e., material) terms and working at different hierarchical levels - but with an eye toward wider anthropological issues of interest.

Clarke referred to some of his central ideas about analysing the structure of the artefactual record as “cultural morphology" ( $A A: 83)$. A better phrase might have been 'the morphology of culture', especially if one takes the effort to understand what Clarke meant by culture as shared information system, and that "morphology" referred to the temporo-spatial material outcomes of this as seen archaeologically, measured at different scales. For Clarke, culture was an "information system" 
comprised of ideas and "learned modes of behaviour and its material manifestations, socially transmitted from one generation to the next and from one society or individual to another" ( $A A$ : 19). This essential component is the one upon which the entire book hangs.

This connection with culture as socially transmitted information and measurable archaeologically as changing spatio-temporal patterns, immediately connected $A A$ with earlier generations of archaeologists of the 'culture historical' tradition. As Shennan (1989: 834) noted, "Clarke took culture seriously in the same way as traditional [i.e., culture historical] approaches had done and New Archaeology has not." Equally, as Sherratt (1979: 197) noted, in this sense $A A$ simultaneously "looked both to the past and the future". That Clarke drew some inspiration for the statistical and methodological aspects of $A A$ from work that had recently been undertaken by North American archaeologists has been noted for some time (Chapman 1979: 124). Equally, suggestions that $A A$ connected in some ways with an intellectual tradition derived from Gordon Childe has also been made (Chapman 1979: 123; Shennan 1989: 833). However, philosophically, even stronger ties to ideas from earlier American anthropologists such as Alfred Kroeber (four of whose works are cited in $A A$ compared with just a single source for Childe) are also readily apparent throughout the book. This is especially the case with reference to the transmission and diffusion of culture seen archaeologically in artefactual patterns through time and space. With some rare exceptions, such as Deetz's Invitation to Archaeology (published just months earlier and bearing some abbreviated similarities to $A A$ ) this was contradictory to the scorched-earth policy of the New Archaeology. Accordingly, this element of Clarke's philosophy drew strong criticism from Binford (1972). In the years that followed, the central role of culture as information system and the relationship of this to artefacts, their traits and wider spatial and temporal patterns was the most unexplored aspect of $A A$ (Shennan 1989). While successful in tackling other questions, 'Processual Archaeology' rendered much of this unfashionable, if not instilling the notion of 'culture history' as a dirty word; antiquated, theoretically ill-informed and, therefore, irrelevant.

While $A A$ can be seen as emphasizing the examination of patterns of form over space and time in line with preceding approaches (see e.g., Lyman et al. 1997), Clarke explicitly called for an increase in the precision and sophistication by which archaeological patterns and the processes involved in their formation were logically conceived, described, quantified and analysed. In regard 
to his critique of certain preceding ways in which this had been done archaeologically, Clarke himself cannot be accused of being coy $(A A$ : xiii, 131; 1973).

Analytical archaeology and cultural-evolutionary archaeology: a recent descendant?

"The primary processes are those of inevitable variation, multilinear development [branching lineages of cultural transmission], invention, diffusion and cultural selection. Combined in many permutations and circumstances these processes give rise to such complex processes as acculturation, and cultural growth, decay and disintegration. ” D.L. Clarke, $A A: 22$

Given much of the foregoing, the overlap between some of the central tenets of Clarke's approach as described in $A A$ and recent work that has sometimes been labelled as 'evolutionary archaeology' will be apparent. Indeed, those working in this broad framework have often readily acknowledged this connection on some level (e.g., O'Brien and Lyman 2000; Shennan 2002, 2004; Lycett 2015). Contemporary approaches to cultural evolution, of which evolutionary archaeology is part, follow Darwin in emphasising that evolution is a process of 'descent with modification' based on heritable variation and the differential replication of that variation across time and space. Such principles were also at the core of $A A$. Clarke $(A A: 152)$ noted how "[v]ariation is inevitable among artefacts and their attributes, and population level variation is the basis of developmental change." For Clarke (AA: 161), some of this inevitable variation was the result of human ingenuity and invention, as the quote at the top of this section highlights, yet importantly, some of this was also due to stochastic factors "from human inability to reproduce repeatedly and exactly ... even when exact replication is desired." Through social learning meanwhile, "the population entity has a 'heredity' - and antecedent trajectory" ( $A A$ : 134) but the "inevitable variation is the basis of developmental change, providing the mechanism by means of which one artefact type or assemblage develops into another" (AA: 161).

Cultural-evolutionary approaches have actively pursued many of these lines of thought in recent years. Space precludes anything like a full review (see Shennan 2011; Mesoudi 2011; Lycett 2015; for a range of relevant examples appearing within the last 20 years). However, evolutionary archaeologists have demonstrated renewed interest in tracking social transmission and its material outcomes (e.g., Lipo et al. 1997; Bettinger and Eerkens 1999; Kohler et al. 2004; Buchanan and Hamilton 2009; Shennan et al. 2015), examining lineages of transmission and their divergence, dispersal and convergence (e.g., O'Brien et al. 2001; Harmon et al. 2006; Lipo et al. 2006; VanPool 
et al. 2008; Jennings and Waters 2014; Prentiss et al. 2015), looking at spatio-temporal variation in artefacts using evolutionary models and principles (e.g., Neiman 1995; Lyman et al. 2009; Lipo et al. 2010; Okumura and Araujo 2014; Eren et al. 2015; Buchanan et al. 2016), studying variation in the context of drift and selection (e.g., Shennan and Wilkinson 2001; Lycett 2008; Brantingham and Perreault 2010; Cochrane et al. 2013) and in using ethnographic and ethnohistorical datasets to inform understanding of artefact variation and its behaviour when subject to evolutionary forces (Jordan and Shennan 2003; Rogers et al. 2009; Tehrani et al. 2010; Jordan 2015; Lycett 2017). Computer simulation, an approach that Clarke recognised the future value of, has also been used to model issues at the heart of the approach outlined in $A A$ (e.g., Neiman 1995; Crema et al. 2014; Rorabaugh 2014) and the role of copying error in artefact traditions is receiving greater consideration (e.g., Eerkens 2000; Eerkens and Lipo 2005; Hamilton and Buchanan 2009; Kempe et al. 2012; Schillinger et al. 2016). In sum, there is much here that we might recognize as being connected to key elements of concern to Clarke as described in $A A$.

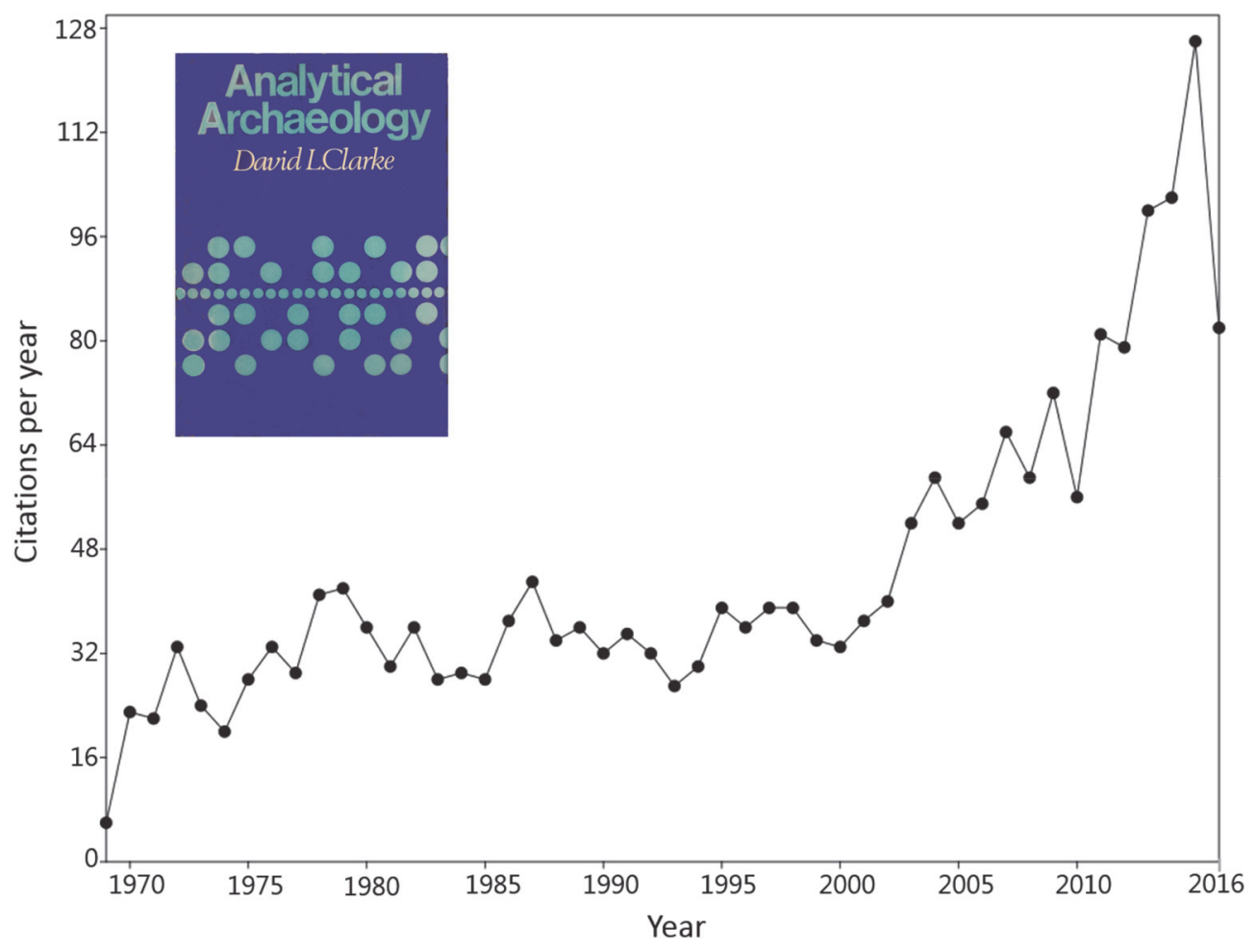

Figure 1: Citations received for D.L. Clarke's (1968) Analytical Archaeology 1969-2016. Data retrieved from Google Scholar (August 2017). 
A pertinent question is to what extent this recent work is a direct result of inspiration from Clarke. More pointedly, is there now reason to challenge Shennan's (1989: 831) assertion that $A A$ "had virtually no influence whatsoever"? In recent years, $A A$ has certainly seen a steep rise in the regularity with which it is cited (Figure 1). Citation of $A A$ remained steady but modest until the mid-2000s, at less than 50 per year. Only in the last decade and a half has there been a marked rise in citation, although this rise has been dramatic, with the number of citations in 2015 almost quadrupling the average received c.1969-2003 (Figure 1). However, such data must be tempered by consideration of the rate of increased publication within the last two decades, and many similar exercises of this type reveal an increase in citation during these years. There are many reasons that authors may have cited $A A$, both positively and negatively, especially given the rise in use of computing methodologies and spatial analysis that has occurred in recent years. Moreover, Sinclair (2016) has pointed out that classic archaeological works might come to function as "concept symbols" (sensu Small 1978), whereupon they merely serve as the standard reference for general points or concepts (such as possibly 'Processual archaeology' or 'systems theory' in Clarke's case) rather than something more substantive based on an original and detailed reading of the publication. Clearly, there is a danger of caricature in such patterns.

As we have noted, some workers within evolutionary archaeology readily acknowledge some influence (at least in an historical sense) from Clarke (e.g., O'Brien and Lyman 2000; Shennan 2002, 2004; Lycett 2015). Other key works and summaries in this genre, however, do not reference $A A$ at all (e.g., Leonard 2001; Eerkens and Lipo 2007; Stark et al. 2008; Jordan 2015). We do not imply criticism here, merely observation. Indeed, perhaps more correctly, the majority of works in evolutionary archaeology frequently list more recent works outside of archaeology as sources of influence and inspiration (e.g., Cavalli-Sforza and Feldman 1981; Boyd and Richerson 1985); a line of inspiration that follows the explosion of evolutionary work in the social sciences in recent years (Bortolini et al. 2017; Mesoudi 2017). Furthermore, Sinclair's (2016: Table 6) citation network analysis of archaeological research published between 2004-2013 does not indicate a particularly strong connection between Clarke and evolutionarily minded authors, but between Clarke and authors associated with more general theoretical issues. In other words, citation practices might suggest there is as much convergence in any similarity with themes discussed in $A A$ as direct descent. 
Part of the reason for this historical and practical disconnect between $A A$ and current cultural evolutionary work in archaeology (at least to the extent that it is not more routinely recognized) may lie with Clarke himself. As O'Brien and Lyman (2000: 261-262) note, $A A$ did not use the word 'evolution' to describe the processes outlined, and mentioned Darwin only in passing and without direct citation ( $A A$ : 515). Perhaps coincidentally, however, the title may have been inspired by Sommerhoff's (1950) Analytical Biology, which is also cited in passing (AA: 406). We can only guess at why Clarke was so coy, but it may have been a reluctance (see above) to imply that archaeology could wholesale adopt the theory and methods of another discipline, rather than do the work of incorporating what is useful and formulating its own. Nevertheless, this does ensure that the reader has to work hard to make the connection with evolutionary theory, and indeed probably understand it quite well before fully appreciating this connection.

In addition, the sheer sophistication of what Clarke proposed in terms of looking at various scales of archaeological data by means of spatial and temporal patterns through statistical and quantitative models, was ahead of the technology of the time. While Clarke was prophetic in terms of his predictions about the influence of computing methods in archaeology, these did not assume their current prominence until the age of affordable desktop computing, user-friendly software and the internet. Clarke's vision for archaeology as outlined in $A A$ was as technologically constrained as astronomy without a telescope. Instructively, cultural-evolutionary approaches in archaeology, which draw heavily on these methods, have a correlated rise to prominence within the field.

The circuitous relationship that $A A$ has with (cultural) evolutionary theory, also demonstrates, however, that it is possible to discuss what is effectively an evolutionary approach to material culture, without overt mention of terms such as 'natural selection' or 'adaptation', at least not in the sense that knee-jerk rejections of such an approach invariably leap upon. Perhaps most fascinatingly, Clarke talked about forces involved in cultural evolution in terms that postprocessual archaeologists might recognise. Indeed, this connection is something that postprocessualists have on occasion themselves pointed out (e.g., Hodder 1991: 189; Parker-Pearson 1998: 680-681). As demonstrated by Clarke's statement that "“culture' consists of learned modes of behaviour and its material manifestations", he viewed artefacts as an inherent part of what he labelled 'culture', not as something separate and only passively reflecting it ( $A A$ : 19). To the contrary, Clarke observed " $[\mathrm{t}]$ he least appreciated and most subtle role of material artefacts is their 
capacity for information communication, a symbolic and evocative role impinging on the psychological subsystem of the society itself - in a continuous feedback loop" (AA:399-400). More colourfully, he suggested "the production of a concomitant set of artefacts constitutes the transmission of information or message ... A child brought up amongst motor-cars and skyscrapers is differently informed to another child born amongst stone axes and pig hunts" (AA: 86). However, for Clarke, and in line with his implicit evolutionary approach, the representation or fate of these ultimately depended on "the ordered selection of a set of attributes from the infinite variety of possible cultural expressions" ( $A A: 86)$. Such selection might on occasion appear irrational from the viewpoint of natural selection alone $(A A: 115)$, for people make these decisions based on attitudes shaped by prevailing cultural attitudes ( $A A$ : 113). In sum, at least some of these themes (material culture is active, human agency can be as powerful a force in culture change as ecological parameters) are shared between post-processual archaeology and $A A$. What is not shared, is the means by which these issues are approached analytically. Again, there is arguably a greater connection with Clarke's line of thinking on these matters and discussions within evolutionary archaeology of cultural selection or 'biases' that shape cultural patterns in ways that are quantifiable and amenable to statistical analysis, (e.g., Shennan and Wilkinson 2001; Shennan 2011: 1071; Jordan 2015: 34, 371-373; Lycett 2015).

\section{Conclusions}

Sherratt (1976) suggested that $A A$ "was the delight of the imaginative and the despair of the pedantic". It is likely to remain so. Does $A A$ still "have no influence whatsoever" as Shennan (1989) asserted? Our longer term evaluation indicates a qualified, but firm, no. 'Qualified', because in so many ways much of what Clarke outlined in $A A$ has taken hold in some form, but this is likely independent of, or even despite of, rather than because of its presence. This also means, however, that there are multiple reasons for the current and new generations to return to the book. In many respects, the current generation of archaeologists may be intellectually and technically more 'pre-adapted' to the ideas contained in $A A$, and certainly more technologically equipped to implement them, than any other previous generation. $A A$ undoubtedly requires patient and dedicated unpacking. However, we suspect there is a wealth of worthwhile ideas still awaiting discovery and pursuance within it. 


\section{Acknowledgements}

We are grateful to Chantal Conneller and two anonymous WA reviewers for insightful and helpful comments on the text. SJL thanks Metin Eren, Alastair Key, Kerstin Schillinger and Noreen von Cramon-Taubadel for many valuable conversations and comments relating to Clarke's work.

\section{References}

Bettinger, R.L. and Eerkens, J. 1999. Point typologies, cultural transmission, and the spread of bow-andarrow technology in the prehistoric Great Basin. American Antiquity, 64: 231-242.

Binford, L.R. 1962. Archaeology as anthropology. American Antiquity, 28: 217-225.

Binford, L.R. 1972. Contemporary model building: paradigms and the current state of Palaeolithic research. In Models in Archaeology (ed D.L. Clarke). London: Methuen, pp.109-166.

Binford, S.R. and Binford, L.R. (ed.). 1968. New Perspectives in Archaeology. Chicago: Aldine.

Bortolini, E., Paganim, L., Crema, E.R., Sarno, S., Barbieri, C., Boattini, A., Sazzini, M., da Silva, S.G., Martini, G., Mespalu, M., Pettener, D., Luiselli, D., Tehrani, J.J. 2017. Inferring patterns of folktale diffusion using genomic data. Proceedings of the National Academy of Science USA doi: $10.1073 /$ pnas. 1614395114.

Boyd, R. and Richerson, P.J. 1985. Culture and the Evolutionary Process. Chicago: University of Chicago Press.

Brantingham, P.J. and Perreault, C. 2010. Detecting the effects of selection and stochastic forces in archaeological assemblages. Journal Archaeological Science, 37: 3211-3225.

Buchanan, B. and Hamilton, M. 2009. A formal test of the origin of variation in North American early Paleoindian projectile points. American Antiquity, 74: 279-298.

Buchanan, B., Hamilton, M.J., Kilby, J.D. and Gingerich, J.A. 2016. Lithic networks reveal early regionalization in late Pleistocene North America. Journal of Archaeological Science, 65: 114-121.

Cavalli-Sforza, L.L. and Feldman, M.W. 1981. Cultural Transmission and Evolution: A Quantitative Approach. Princeton, NJ: Princeton University Press.

Chapman, R. 1979. 'Analytical Archaeology' and after. In Hammond, N., Isaac, G., Chapman, R., Sherratt, and Shennan, S. (Eds.), Analytical Archaeologist: London: Academic Press, pp.109-144.

Clarke, D.L. 1968. Analytical Archaeology. London: Methuen.

Clarke, D.L. 1973. Archaeology: the loss of innocence. Antiquity, 47: 6-18.

Cochrane, E.E., Rieth, T.M. and Dickinson, W.R. 2013. Plainware ceramics from Sāmoa: insights into ceramic chronology, cultural transmission, and selection among colonizing populations. Journal of Anthropological Archaeology, 32: 499-510.

Crema, E.R., Kerig, T. and Shennan, S. 2014. Culture, space, and metapopulation: a simulation-based study for evaluating signals of blending and branching. Journal of Archaeological Science, 43: 289-298.

Deetz, J. 1967. Invitation to Archaeology. New York: The Natural History Press. 
Eerkens, J.W. 2000. Practice makes within 5\% of perfect: visual perception, motor skills, and memory in artifact variation. Current Anthropology, 41: 663-668.

Eerkens, J.W. and Lipo, C.P. 2005. Cultural transmission, copying errors, and the generation of variation in material culture and the archaeological record. Journal of Anthropological Archaeology, 24: 316-334.

Eerkens, J.W. and Lipo, C.P. 2007. Cultural transmission theory and the archaeological record: context to understanding variation and temporal changes in material culture. Journal of Archaeological Research, 15: 239-274.

Eren, M.J., Buchanan, B. and O’Brien, M.J. 2015. Social learning and technological evolution during the Clovis colonization of the New World. Journal of Human Evolution, 80: 159-170.

Griffiths, S. 2017. We're all cultural historians now: revolutions in understanding archaeological theory and scientific dating. Radiocarbon, 59: 1347-1357.

Hamilton, M.J. and Buchanan, B. 2009. The accumulation of stochastic copying errors causes drift in culturally transmitted technologies: quantifying Clovis evolutionary dynamics. Journal of Anthropological Archaeology, 28: 55-69.

Hammond, N., Isaac, G., Chapman, R., Sherratt, A. and Shennan, S. (Eds.) 1979. Analytical Archaeologist: Collected Papers of David L. Clarke. London: Academic Press.

Harmon, M.J., Van Pool, T.L., Leonard, R.D., Van Pool, C.S., and Salter, L.A. 2006. Reconstructing the flow of information across time and space: a phylogenetic analysis of ceramic traditions from preHispanic western and northern Mexico and the American southwest. In Mapping Our Ancestors: Phylogenetic Approaches in Anthropology and Prehistory (eds C.P. Lipo, M.J. O'Brien, M. Collard, S. Shennan). New Brunswick: Aldine Transaction, pp. 209-229.

Hodder, I. 1991. Reading the Past. Cambridge: Cambridge University Press.

Hodder, I., Isaac, G. and Hammond, N. 1981. Pattern of the Past: Studies in Honour of David Clarke. Cambridge: Cambridge University Press.

Jennings, T.A. and Waters, M.R. 2014. Pre-Clovis lithic technology at the Debra L. Friedkin site, Texas: Comparisons to Clovis through site-level behavior, technological trait-list, and cladistic analyses. American Antiquity 79: 25-44.

Johnson, M. 1999. Archaeological Theory: An Introduction. Oxford: Blackwell.

Jordan, P. 2015. Technology as Human Social Tradition: Cultural Transmission among Hunter-Gatherers. Berkeley: University of California Press.

Jordan, P. and Shennan, S. 2003. Cultural transmission, language, and basketry traditions amongst the California Indians. Journal of Anthropological Archaeology, 22: 42-74.

Kempe, M., Lycett, S.J. and Mesoudi, A. 2012. An experimental test of the accumulated copying error model of cultural mutation for Acheulean handaxe size. PLoS One, 7: e48333.

Kohler, T.A., Van Buskirk, S. and Ruscavage-Barz, S. 2004. Vessels and villages: evidence for conformist transmission in early village aggregations on the Pajarito Plateau, New Mexico. Journal of Anthropological Archaeology, 23: 100-118.

Leonard, R.D. 2001. Evolutionary archaeology. In Archaeological Theory Today (ed I. Hodder), Oxford: Polity/Blackwell, pp.65-97. 
Lipo, C.P., Madsen, M.E., Dunnell, R.C. and Hunt, T. 1997. Population structure, cultural transmission, and frequency seriation. Journal of Anthropological Archaeology, 16: 301-333.

Lipo, C.P., O'Brien, M.J., Collard, M. and Shennan, S. 2006. Cultural phylogenies and explanation: why historical methods matter. In Mapping Our Ancestors: Phylogenetic Approaches in Anthropology and Prehistory (Eds Lipo, C.P., O'Brien, M.J., Collard, M., Shennan, S.). New Brunswick: Aldine Transaction, pp. 3-16.

Lipo, C.P., Hunt, T.L. and Hundtoft, B. 2010. Stylistic variability of stemmed obsidian tools (mata'a), frequency seriation, and the scale of social interaction on Rapa Nui (Easter Island). Journal of Archaeological Science, 37: 2551-2561.

Lycett, S.J. 2008. Acheulean variation and selection: does handaxe symmetry fit neutral expectations? Journal of Archaeological Science, 35: 2640-2648.

Lycett, S.J. 2015. Cultural evolutionary approaches to artifact variation over time and space: basis, progress, and prospects. Journal of Archaeological Science, 56: 21-31.

Lycett, S.J. 2017. Cultural patterns within and outside of the post-contact Great Plains as revealed by parfleche characteristics: Implications for areal arrangements in artifactual data. Journal of Anthropological Archaeology, 48: 87-101.

Lyman, R.L., O’Brien, M.J. and Dunnell, R.C. 1997. Americanist Culture History: Fundamentals of Time, Space, and Form. New York: Plenum Press.

Lyman, R.L., Vanpool, T.L. and O'Brien, M.J.. 2009. The diversity of North American projectile-point types, before and after the bow and arrow. Journal of Anthropological Archaeology, 28: 1-13.

Mesoudi, A. 2011. Cultural Evolution: How Darwinian Theory can Explain Human Culture and Synthesize the Social Sciences. Chicago University Press, Chicago.

Mesoudi, A. 2017. Pursuing Darwin's curious parallel: prospects for a science of cultural evolution. Proceedings of the National Academy of Sciences, 114: 7853-7860.

Neiman, F.D. 1995. Stylistic variation in evolutionary perspective: inferences from decorative diversity and interassemblage distance in Illinois Woodland ceramic assemblages. American Antiquity, 60: 7-36.

O'Brien, M.J. 2010. The future of Paleolithic studies: A view from the New World. In New Perspectives on Old Stones: Analytical Approaches to Paleolithic Technologies (eds S.J. Lycett and P.R. Chauhan). New York: Springer, pp. 311-334.

O’Brien, M.J. and Lyman, R.L. 2000. Applying Evolutionary Archaeology: A Systematic Approach. Plenum, New York.

O'Brien, M.J., Darwent, J. and Lyman, R.L. 2001. Cladistics is useful for reconstructing archaeological phylogenies: Palaeoindian points from the southeastern United States. Journal of Archaeological Science, 28: 1115-1136.

Okumura, M. and Araujo, A.G. 2014. Long-term cultural stability in hunter-gatherers: a case study using traditional and geometric morphometric analysis of lithic stemmed bifacial points from Southern Brazil. Journal of Archaeological Science, 45: 59-71.

Parker-Pearson, M. 1998. The beginning of wisdom. Antiquity, 72: 680-686.

Prentiss, A.M., Walsh, M.J., Foor T.A. and Barnett, K.D.. 2015. Cultural macroevolution among high latitude hunter-gatherers: a phylogenetic study of the Arctic Small Tool tradition. Journal of Archaeological Science, 59: 64-79. 
Rogers, D.S., Feldman, M.W. and Ehrlich, P.R. 2009. Inferring population histories using cultural data. Proceedings of the Royal Society B, 276: 3835-3843.

Rorabaugh, A.N. 2014. Impacts of drift and population bottlenecks on the cultural transmission of a neutral continuous trait: an agent based model. Journal of Archaeological Science, 49: 255-264.

Schillinger, K., Mesoudi, A. and Lycett, S.J. 2016. Copying error, evolution, and phylogenetic signal in artifactual traditions: an experimental approach using "model artifacts." Journal of Archaeological Science, 70: 23-34.

Shennan, S.J. 1989. Archaeology as archaeology or as anthropology? Clarke's Analytical Archaeology and the Binfords' New Perspectives in Archaeology 21 years on. Antiquity, 63: 831-835.

Shennan, S.J. 2002. Genes, Memes and Human History: Darwinian Archaeology and Cultural Evolution. London: Thames and Hudson.

Shennan, S.J. 2004. Analytical archaeology. In A Companion to Archaeology (ed J. Bintliff). Oxford: Blackwell, pp. 3-20.

Shennan, S.J. 2011. Descent with modification and the archaeological record. Philosophical Transactions of the Royal Society B, 366: 1070-1079.

Shennan, S.J. and Wilkinson, J.R. 2001. Ceramic style change and neutral evolution: a case study from Neolithic Europe. American Antiquity, 66: 577-593.

Shennan, S.J., Crema, E. and Kerig, T. 2015. Isolation-by-distance, homophily, and 'core' vs. 'package' cultural evolution models in Neolithic Europe. Evolution and Human Behavior, 36: 103-109.

Sherratt, A. 1976. Obituary: David Clarke. Nature, 262: 634.

Sherratt, A. 1979. Problems in European prehistory. In Analytical Archaeologist (eds N. Hammond, G. Isaac, R. Chapman, Sherratt, A. and S. Shennan). London: Academic Press, pp.193-206.

Small, H.G. Cited documents as concept symbols. Social Studies of Science, 8: 327-340.

Sinclair, A. 2016. The intellectual base of archaeological research 2004-2013: a visualisation and analysis of its disciplinary links, networks of authors and conceptual language. Internet Archaeology 42 https://doi.org/10.11141/ia.42.8

Stark, M.T., Bowser, B.J. and Horne, L. 2008. Cultural Transmission and Material Culture: Breaking Down Boundaries. Tucson: University of Arizona Press.

Sommerhoff, G. 1950. Analytical Biology. Oxford: Oxford University Press.

Tehrani, J.J., Collard, M. and Shennan, S.J. 2010. The co-phylogeny of populations and cultures: reconstructing the evolution of Iranian tribal craft traditions using trees and jungles. Philosophical Transactions of the Royal Society B, 365: 3865-3874.

Trigger, B.G. 1989. A History of Archaeological Thought. Cambridge: Cambridge University Press.

Vanpool, T.L., Palmer, C.T. and Vanpool, C.S.. 2008. Horned serpents, tradition, and the tapestry of culture. In Cultural Transmission and Archaeology: Issues and Case Studies (ed M.J. O'Brien). Washington, D.C.: Society for American Archaeology Press, pp. 77-90.

Willey, G.R. and Phillips, P. 1958. Method and Theory in Archaeology. Chicago: University of Chicago Press. 